\title{
STAT3 inhibition by WP1066 suppresses the growth and invasiveness of bladder cancer cells
}

\author{
YUJIRO TSUJITA $^{1}$, AKIO HORIGUCHI ${ }^{1}$, SHINSUKE TASAKI ${ }^{1}$, MAKOTO ISONO ${ }^{1}$, TAKAKO ASANO ${ }^{1}$, \\ KEIICHI ITO ${ }^{1}$, TOMOHIKO ASANO ${ }^{1}$, YOSHINE MAYUMI ${ }^{2}$ and TOSHIHIRO KUSHIBIKI ${ }^{2}$ \\ Departments of ${ }^{1}$ Urology and ${ }^{2}$ Medical Engineering, National Defense Medical College, \\ Tokorozawa, Saitama 359-8513, Japan
}

Received April 1, 2017; Accepted August 4, 2017

DOI: $10.3892 /$ or.2017.5902

\begin{abstract}
Signal transducer and activator of transcription 3 (STAT3) regulates the expression of genes mediating cell survival, proliferation and angiogenesis and is aberrantly activated in various types of malignancies, including bladder cancer. We examined whether it could be a novel therapeutic target for bladder cancer using the STAT3 inhibitor WP1066. In T24 and UMUC-3 bladder cancer cells, $5 \mu \mathrm{M}$ WP1066 prevented the phosphorylation of STAT3 and $2.5 \mu \mathrm{M}$ WP1066 decreased cell survival and proliferation significantly $(\mathrm{P}<0.01)$. WP1066 also induced apoptosis accompanied by the suppression of the expression of Bcl-2 and Bcl-xL in T24 cells. Moreover, the covered area in a wound and the number of cells invading through a Matrigel chamber decreased significantly $(\mathrm{P}<0.01)$ when cells were treated with WP1066. The activities of MMP-2 and MMP-9 were also decreased by treatment with $10 \mu \mathrm{M}$ WP1066. Our results revealed that using WP1066 to inhibit the STAT3 signaling pathway suppressed the viability and invasiveness of bladder cancer cells effectively and could be a novel therapeutic strategy against bladder cancer.
\end{abstract}

\section{Introduction}

The clinical outcome of muscle-invasive bladder cancer is poor: approximately half the patients treated by radical cystectomy develop metastases within 2 years, and without other treatment the 5-year survival rate after surgery is $~ 50 \%(1,2)$. Metastatic bladder cancer is a chemosensitive disease and systemic cisplatin-based combination chemotherapy is the first-line treatment modality for it. Despite response rates of $40-60 \%$ achieved by cisplatin-based chemotherapy, in most patients the disease may progress after a median time of

Correspondence to: Dr Akio Horiguchi, Department of Urology, National Defense Medical College, 3-2 Namiki, Tokorozawa, Saitama 359-8513, Japan

E-mail: impreza@ndmc.ac.jp

Key words: urothelial carcinoma, STAT3, invasion, proliferation, apoptosis $\sim 8$ months (3). Targeted molecular therapy interfering with cellular processes essential for cancer growth has been introduced as a novel treatment strategy during the last 2 decades, but no targeted agent approved for bladder cancer treatment has yet emerged (4).

The signal transducer and activator of transcription (STAT) proteins are involved in cytokine- and growth factor-induced signal transduction (5). These latent cytoplasmic transcription factors become activated through tyrosine phosphorylation typically catalyzed by cytokine-receptor-associated kinases, Janus kinases (Jak), or growth factor receptor tyrosine kinases and are translocated to the nucleus to activate target genes (5). One of the STAT proteins, STAT3, was originally identified as an acute-phase response factor activated by the interleukin-6 (IL-6) family of cytokines (6). Further studies have shown that it can be activated by a variety of cytokines and growth factors (7). It regulates the transcription of key components of cell cycle control and modulates the activity of proteins regulating apoptosis, and constitutively activated STAT3 due to aberrantly produced growth cytokines or growth factors which have been reported in a variety of malignant tumors, including bladder cancer (4,8-14). Moreover, activation of STAT3 leads to increased invasiveness of cancer and constitutive activation of STAT3 is associated with advanced cancer stage and metastatic disease (9,14-16). Given these findings, we postulated that STAT3 could be a novel therapeutic target for bladder cancer and in the present study examined whether the STAT3 inhibitor WP1066 exhibited antitumor activity against bladder cancer.

\section{Material and methods}

Cell culture and reagents. Human bladder cancer cell lines T24 and UMUC-3 [American Type Culture Collection (ATCC) Manassas, VA, USA] were maintained in RPMI-1640 supplemented with $10 \%$ fetal bovine serum at $37^{\circ} \mathrm{C}$ in a $5 \%$ $\mathrm{CO}_{2}$ atmosphere. WP1066 (Calbiochem, La Jolla, CA, USA) used in the present study was dissolved in $50 \mathrm{mM}$ of dimethyl sulfoxide (DMSO) and stored at $-20^{\circ} \mathrm{C}$. The antibodies used in the present study were antibodies against phospho-STAT3 (p-STAT3, 1:1,000), STAT3 (1:1,000), phospho-ERK (p-ERK, 1:1,000), ERK (1:1,000), cleaved caspase-3 (1:1,000), cleaved PARP (1:1,000), Bcl-2 (1:1,000), Bcl-xL (1:1,000) (all from 
Cell Signaling Technology, Inc., Danvers, MA, USA), and $\beta$-actin (1:3,000; Chemicon International, Inc., Temecula, CA, USA). Horseradish-peroxidase-conjugated secondary antibodies and an enhanced chemiluminescence system were obtained from Amersham Pharmacia Biotech (Piscataway, NJ, USA).

Western blot analysis. Cells that had been treated with the indicated concentrations of WP1066 or the corresponding amount of DMSO for the indicated time-points were lysed in RIPA buffer $(10 \mathrm{mM}$ Tris-HCl, $150 \mathrm{mM} \mathrm{NaCl}, 1 \%$ Triton X-100, $5 \mathrm{mM}$ EDTA, $1 \%$ sodium deoxycholate, $0.1 \%$ SDS, $1.2 \%$ aprotinin, $5 \mu \mathrm{M}$ leupeptin, $4 \mu \mathrm{M}$ antipain, $1 \mathrm{mM}$ phenylmethylsulfonyl fluoride and $0.1 \mathrm{mM} \mathrm{Na}_{3} \mathrm{VO}_{4}$ ). Equal amounts of the resulting lysates were separated using 10\% SDS-PAGE and transferred to nitrocellulose membranes. The membranes were blocked with a solution containing $5.0 \%$ skim milk, and then incubated with a primary antibody overnight at $4^{\circ} \mathrm{C}$. They were then incubated with a secondary antibody coupled to horseradish peroxidase (Amersham, Arlington Heights, IL, USA). The reactive proteins were visualized using enhanced chemiluminescence according to the manufacturer's recommendations. The relative intensities of protein expression were calculated using the ImageJ program.

Cell counts and cell viability assays. Following incubation overnight in 6 -well plates $\left(5 \times 10^{4}\right.$ cells/well, in triplicate), the cells were treated with WP1066 at the indicated concentrations. The total number of cells in 3 independent wells in each group were counted at the indicated time-points after incubation using a hemocytometer, and the mean value of 4 fields was recorded. The results were expressed as the mean $\pm \mathrm{SE}$ of the total number of cells in each well in each group. Cell viability was assessed by MTS assay using the CellTiter 96 $\mathrm{AQ}_{\text {ueous }}$ Non-Radioactive Cell Proliferation Assay (Promega, Madison, WI, USA) according to the manufacturer's instructions. Briefly, the cells were incubated overnight in 96-well plates $\left(1.5 \times 10^{4}\right.$ cells/well), and were then treated for $24 \mathrm{~h}$ with the indicated concentrations of WP1066 or with the corresponding amount of WP1066-free DMSO. Two hours after adding MTS the plates were read at $490 \mathrm{~nm}$ on a microplate autoreader. The results were expressed as the mean optical density (OD) of the 6-well set for each group, and the plates were assessed twice with similar results.

Cell cycle analysis and determination of apoptosis. Cells were incubated for $24 \mathrm{~h}$ with the indicated concentrations of WP1066 or the corresponding amount of DMSO. Propidium-iodide stained nuclear fractions were obtained and the cell cycle data were acquired using a flow cytometer with CellQuest software (Becton-Dickinson, Heidelberg, Germany). Apoptotic cells were assessed by double-staining with FITC-conjugated Annexin $\mathrm{V}$ and propidium-iodide. This staining was carried out using the Annexin V apoptosis detection kit (Santa Cruz Biotechnology, Inc., Santa Cruz, CA, USA).

Wound healing assay. Cells were grown to confluence on 6 -well tissue culture plates and a wound was made by scraping the middle of the cell monolayer with a P200 pipette tip. After floating cells were removed by extensive

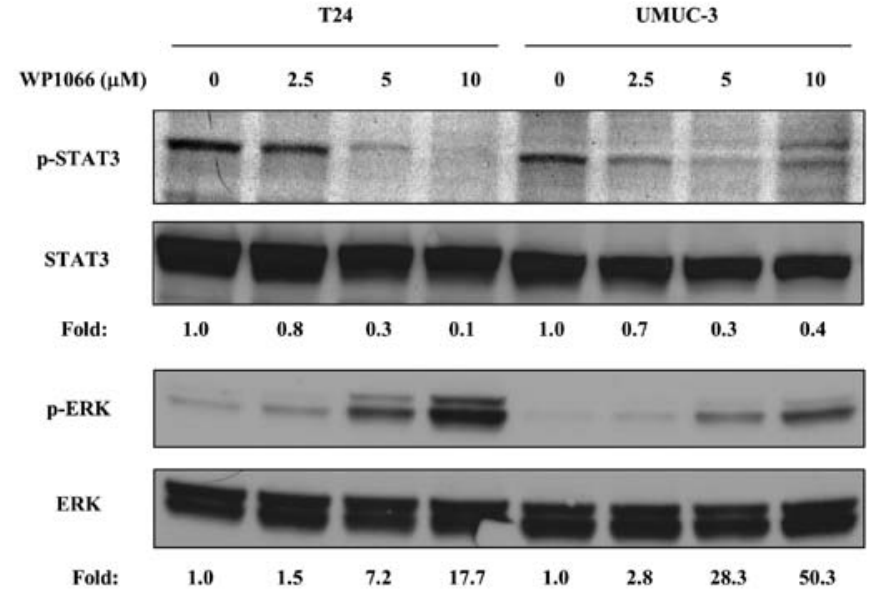

Figure 1.Modulation of intracellular signaling molecules in T24 and UMUC-3 cells treated with the indicated concentrations of WP1066 for $24 \mathrm{~h}$. Total cell lysates were subjected to western blotting. WP1066 inhibited STAT3 phosphorylation while stimulating ERK phosphorylation. The relative intensities of phosphorylated STAT3 and phosphorylated ERK immunoreactive bands are shown. STAT3, signal transducer and activator of transcription 3.

washing with ice-cold phosphate-buffered saline (PBS), fresh complete medium containing WP1066 or the corresponding amount of DMSO was added. Migration and cell movement throughout the wound area were examined after $12 \mathrm{~h}$. The ImageJ program was used to estimate and compare the covered areas (17).

Matrigel invasion assay. An invasion assay was performed using Matrigel-coated Transwell inserts (BD Biosciences, San Diego, CA, USA) with 8- $\mu$ m pores in 24-well plates. Briefly, a suspension of $1 \times 10^{5}$ cells in $500 \mu \mathrm{l}$ serum-free medium was added to the insert, and $750 \mu 1$ serum-free medium supplemented with WP1066 or the corresponding amount of DMSO was added to the bottom of the well. After the plates were incubated for $12 \mathrm{~h}$ at $37^{\circ} \mathrm{C}$, the inserts were fixed in methanol, the filters were stained with $1 \%$ toluidine blue in $1 \%$ borax, and in 3 independent experiments the number of cells that invaded through the Matrigel-coated Transwell inserts was counted in at least 10 fields/well.

Gelatin zymography. Gelatinolytic activity of MMP-2 and MMP-9 was analyzed by gelatin gel zymography using a commercially available kit (code no. AK45; Cosmo Bio Co., Ltd., Tokyo, Japan). In brief, following incubation overnight in 6 -well plates $\left(5 \times 10^{4}\right.$ cells/well), the cells were treated with WP1066 at the indicated concentrations in serum-free medium for $12 \mathrm{~h}$, and then the conditioned medium was collected. Equal amounts of protein from the medium were separated on pre-casted gels containing gelatin. The gels were washed in denaturing buffer for $60 \mathrm{~min}$ at room temperature and then incubated at $37^{\circ} \mathrm{C}$ overnight in developing buffer. They were then stained with $0.25 \%$ Coomassie brilliant blue $\mathrm{R}-250$ for $4 \mathrm{~h}$ at room temperature and destained in distilled water containing $30 \%$ methanol and $10 \%$ glacial acetic acid. The areas where the gelatin substrate had been degraded by gelatinases developed into white lines on a dark background. The relative intensities of gelatinolytic activity were calculated using the Image J program. 
$\mathbf{A}$
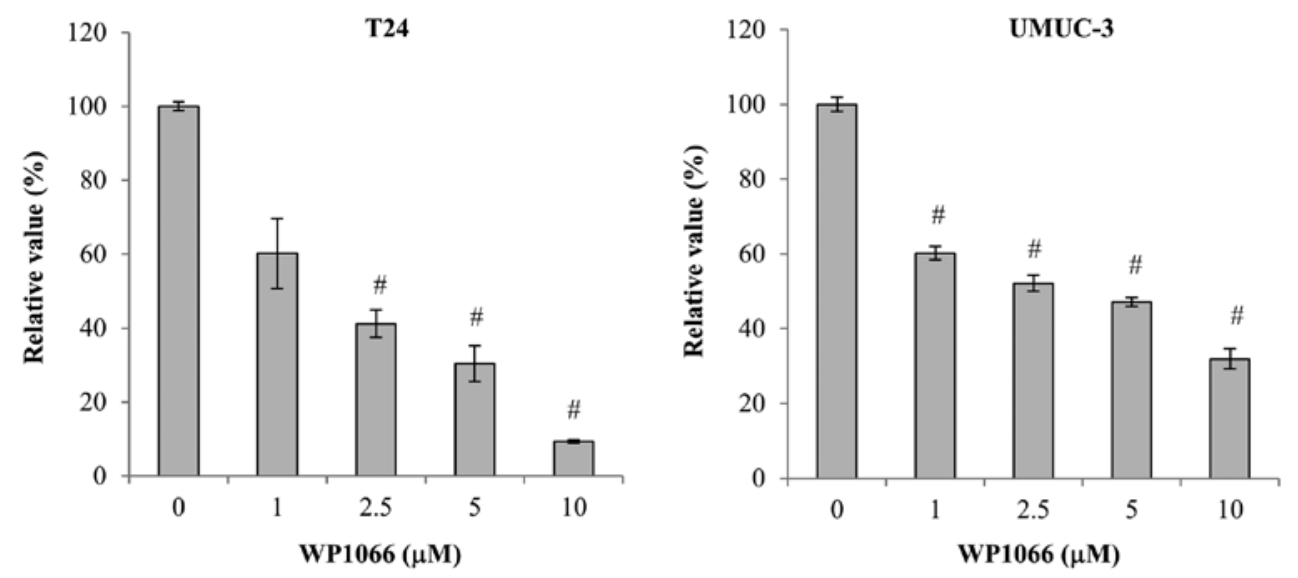

B
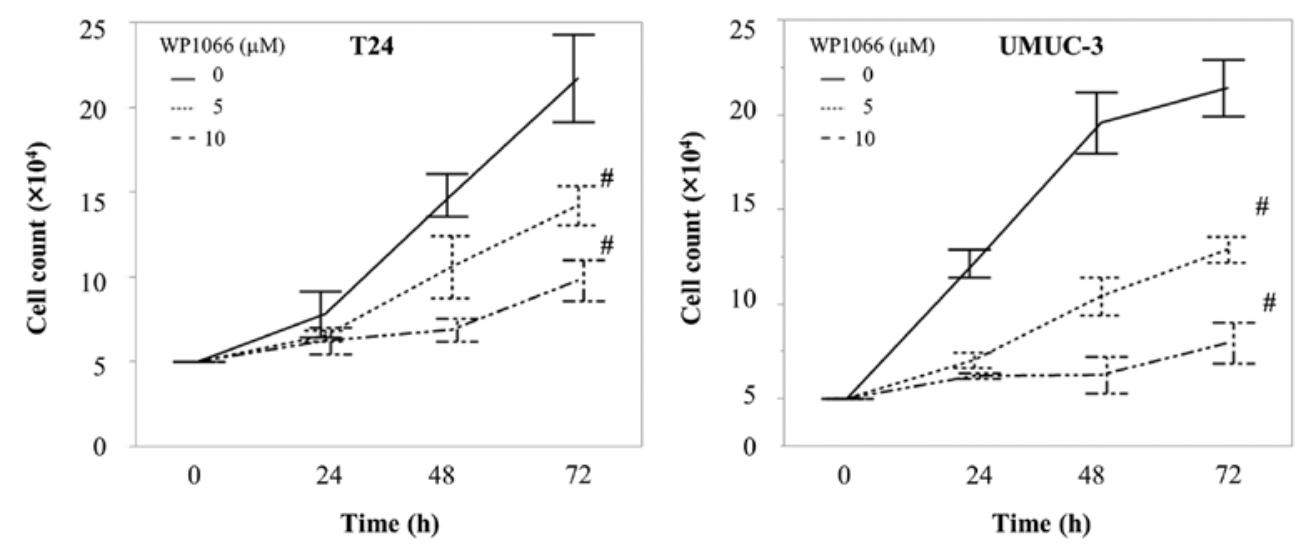

Figure 2. WP1066 significantly decreases the viability and proliferation of bladder cancer cells. (A) An MTS-assay determined the viability of T24 and UMUC-3 cells treated with the indicated concentrations of WP1066 for $24 \mathrm{~h}$. Notably, cell viability was significantly lower in the WP1066-treated cells; ${ }^{\#} \mathrm{P}<0.001$. (B) Proliferation of T24 and UMUC-3 cells treated with the indicated concentrations of WP1066. Notably, proliferation was significantly decreased in the WP1066-treated cells; ${ }^{\text {" }} \mathrm{P}<0.001$.

Statistical analysis. Results are expressed as the mean $\pm \mathrm{SE}$ for 3 independent experiments. Variables for different groups were compared using Student's t-test or analysis of variance (ANOVA), and $\mathrm{P}<0.05$ was considered to indicate a statistically significant result.

\section{Results}

WP1066 inactivates STAT3 in bladder cancer cells. We first tested whether WP1066 inactivated STAT3 in bladder cancer cells. It has been reported that 5-10 $\mu \mathrm{M}$ WP1066 inhibited STAT3 phosphorylation effectively in other cancer cell lines $(18,19)$, thus, we incubated T24 and UMUC-3 cells with $2.5,5$ and $10 \mu \mathrm{M}$ WP1066 for $24 \mathrm{~h}$ and examined the phosphorylation of STAT3 at Tyr705. WP1066 inhibited STAT3 phosphorylation in both cell lines in a dose-dependent manner, and $10 \mu \mathrm{M}$ WP1066 completely abolished it (Fig. 1). Conversely, phosphorylation of ERK, which often acts contrary to STAT3 $(18,20,21)$, was instead increased by WP1066 treatment in a dose-dependent manner (Fig. 1).

WP1066 suppresses bladder cell viability and proliferation by inducing apoptosis. We next examined the ways in which the viability of bladder cancer cells was affected when STAT3 was inhibited by WP1066. We treated T24 and UMUC- 3 cells with 1-10 $\mu \mathrm{M}$ WP1066 for $24 \mathrm{~h}$, and examined their viability by MTS assay. WP1066 significantly suppressed the viability of both T24 and UMUC-3 cells, the former at concentrations $>2.5 \mu \mathrm{M}$ and the latter at concentrations $>1 \mu \mathrm{M}(\mathrm{P}<0.001$; Fig. 2A). In addition, the number of cells present after treatment with 5 or $10 \mu \mathrm{M}$ WP1066 for $72 \mathrm{~h}$ was significantly smaller than that present after incubation without WP1066 $(\mathrm{P}<0.001$; Fig. 2B). We further examined the effect of WP1066 on cell cycle progression by flow cytometry. T24 and UMUC-3 cells were treated with 5 or $10 \mu \mathrm{M}$ WP1066 for $24 \mathrm{~h}$, and their cell cycles were analyzed. In both cell lines the sub-G1 population, which indicates the percentage of apoptotic cells, was significantly increased by WP1066 ( $<<0.001$ in both cell lines; Fig. 3A). To confirm the induction of apoptosis by WP1066 treatment, T24 and UMUC- 3 cells incubated for $24 \mathrm{~h}$ with 5 or $10 \mu \mathrm{M}$ WP1066 were double-stained with Annexin V and propidium iodide and analyzed by flow cytometry. The percentage of the population that was Annexin-positive and propidium iodidenegative, which are apoptotic cells, was significantly greater for cells treated with WP1066 than for control cells $(\mathrm{P}<0.001$ in both cell lines; Fig. 3B). STAT3 has been shown to regulate the expression of apoptosis-related proteins such as Bcl-2 and Bcl-xL $(22,23)$. We further examined the effects of WP1066 on 
A

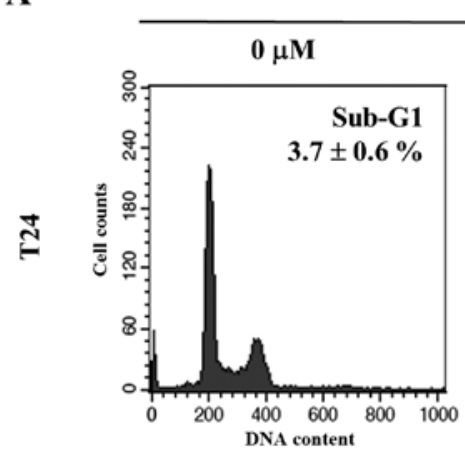

WP1066
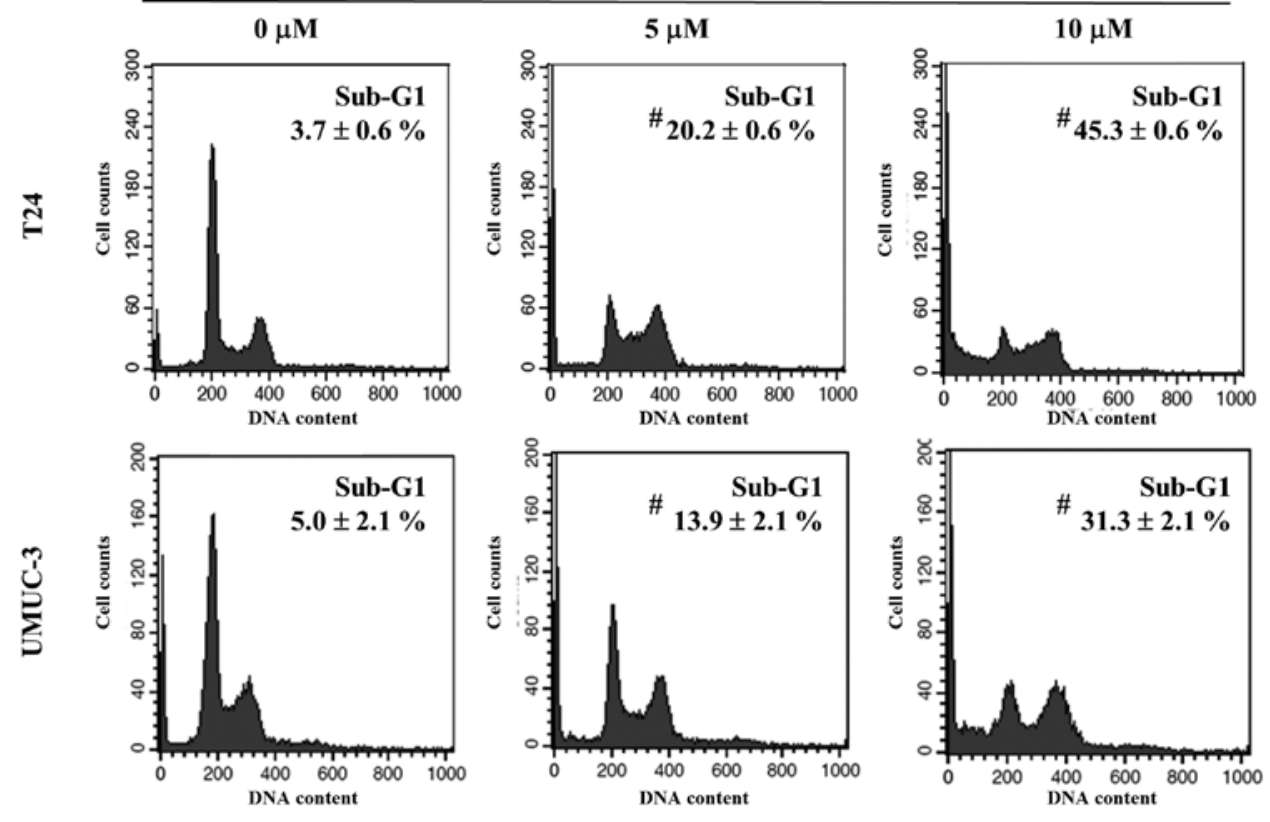

B

WP1066
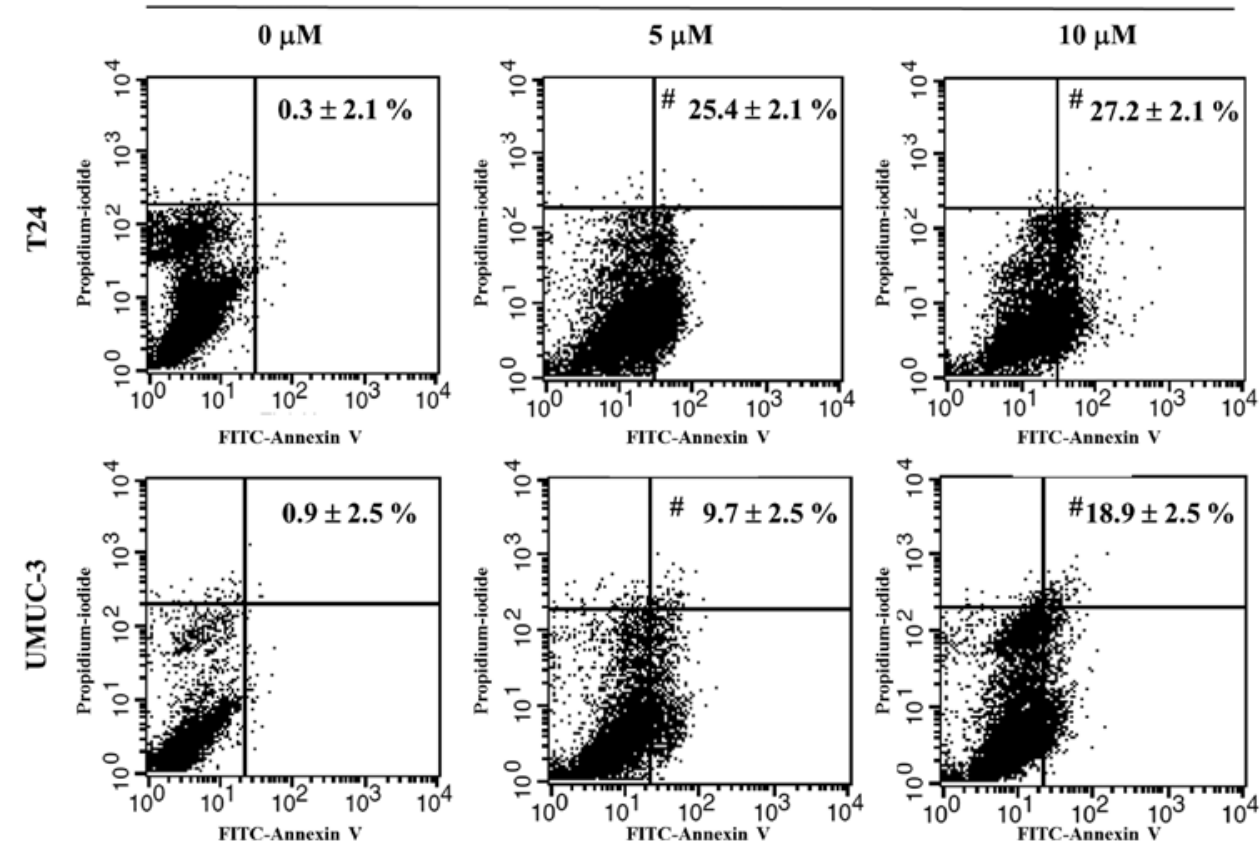

Figure 3. Cell cycle progression inhibition and apoptosis induction caused by WP1066. (A) The cell cycle in T24 and UMUC-3 cells treated with the indicated concentrations of WP1066 for $24 \mathrm{~h}$. Notably, the sub-G1 population was significantly increased with WP1066 treatment in both cell lines; ${ }^{\text {"}} \mathrm{P}<0.001$. (B) Annexin V staining for the apoptosis assay in T24 and UMUC-3 cells incubated for $24 \mathrm{~h}$ with the indicated concentrations of WP1066. The percentage that was Annexin V-positive and propidium-iodide-negative (early apoptosis) was significantly increased with WP1066 treatment in both cells; ${ }^{\#} \mathrm{P}<0.001$.

these apoptosis-related molecules and found that the Bcl-2 and Bcl-xL in T24 cells were decreased with treatment of WP1066, however they were not altered in UMUC-3 cells (Fig. 4). In contrast, cleaved caspase- 3 and cleaved PARP were evident in both T24 and UMUC-3 cells treated with WP1066, which is also evidence that WP1066 induced apoptosis (Fig. 4).

WP1066 decreases the motility and invasiveness of bladder cancer cells. Previous studies have shown that STAT3 promotes cell motility and invasiveness by increasing the activation of matrix metalloproteinases (MMPs), including MMP-2 and MMP-9 (24,25). To assess the effect of WP1066 on the motility and invasiveness of bladder cancer cells, we examined wound healing and used Matrigel invasion assays. Monolayers of T24 and UMUC-3 cells were scraped with the tip of a sterile pipette to create a uniform wound, and then treated with DMSO or 5 or $10 \mu \mathrm{M}$ WP1066 for $12 \mathrm{~h}$ before the covered area was assessed. We chose this treatment time since no significant decrease in the total number of cells was found for either T24 or UMUC-3 cells until $12 \mathrm{~h}$ after 


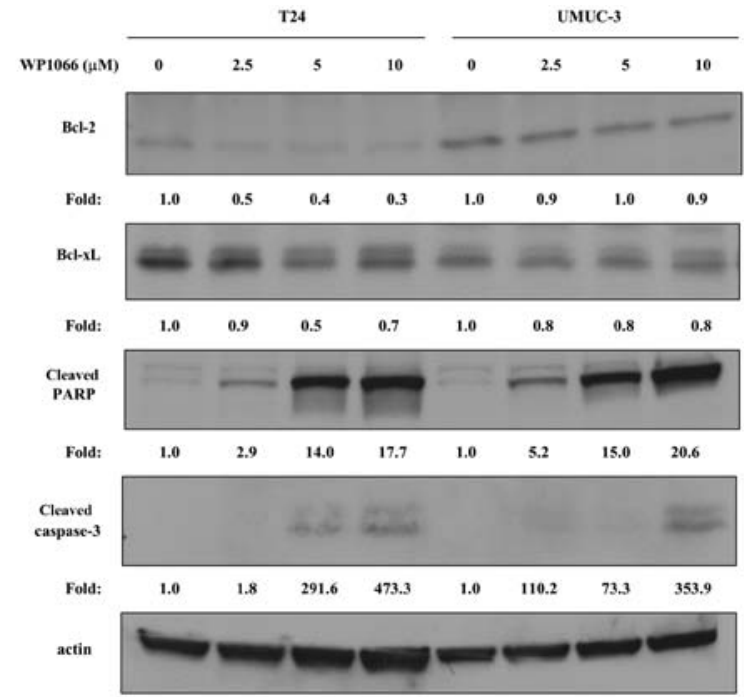

Figure 4. Western blot analysis of apoptosis-related proteins. T24 and UMUC-3 cells were treated with the indicated concentrations of WP1066 for $24 \mathrm{~h}$. Notably, the expression of Bcl-2 and Bcl-xL was decreased and the expression levels of cleaved caspase-3 and cleaved PARP were increased. The relative intensities of immunoreactive bands are shown. Actin was used as an internal control.
WP1066 treatment. In both cell lines, however, the covered area was significantly smaller for WP1066-treated cells than control cells (Fig. 5). In addition, the Matrigel invasion assay demonstrated that the number of T24 and UMUC-3 cells invading through the chamber was significantly decreased by WP1066 (Fig. 6). We further examined the effect of WP1088 treatment on the activities of MMP-2 and MMP-9 by gelatin zymography. Treatment with $10 \mu \mathrm{M}$ WP1066 inhibited the activity of MMP-2 and MMP-9 completely in UMUC-3 cells (Fig. 7). These results revealed that WP1066 decreased the motility and invasiveness of bladder cancer cells by inhibiting MMP activity.

\section{Discussion}

In various types of malignant tumors, including bladder cancer, activation of STAT3 is aberrantly increased and has been reported to be associated with tumor aggressiveness and poor clinical outcome $(7,26,27)$. Degoricija et al examined STAT3 gene expression in 36 bladder cancer tissues and found that it was upregulated in 27 (75\%) (26). Chen et al examined STAT3 activation in 100 bladder cancer

A
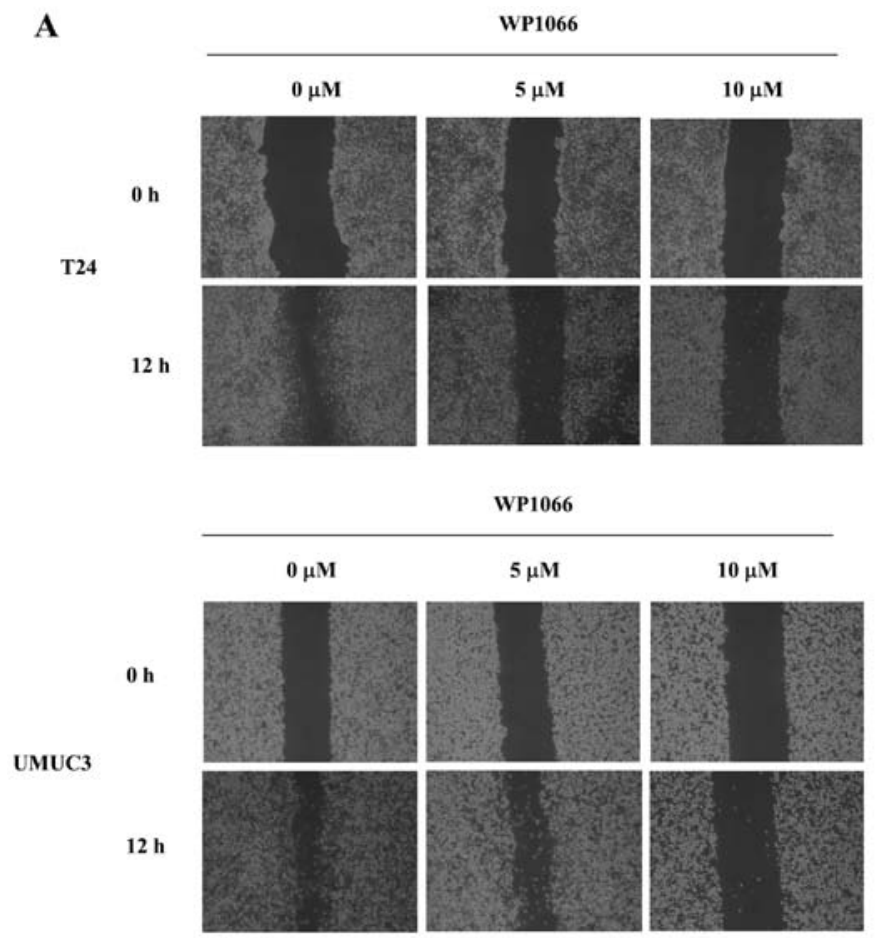

B

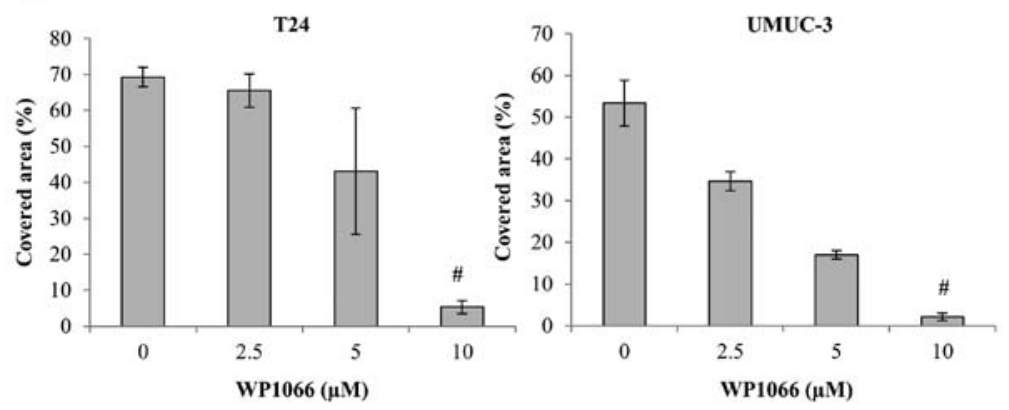

Figure 5. WP1066 suppresses the mobility of bladder cancer cells. (A) Representative images of wound closure and (B) summary of coverage data for monolayers of T24 and UMUC-3 cells scraped with a pipette tip and treated with the indicated concentrations of WP1066 for $12 \mathrm{~h}$; ${ }^{\# P}<0.01$. 
A
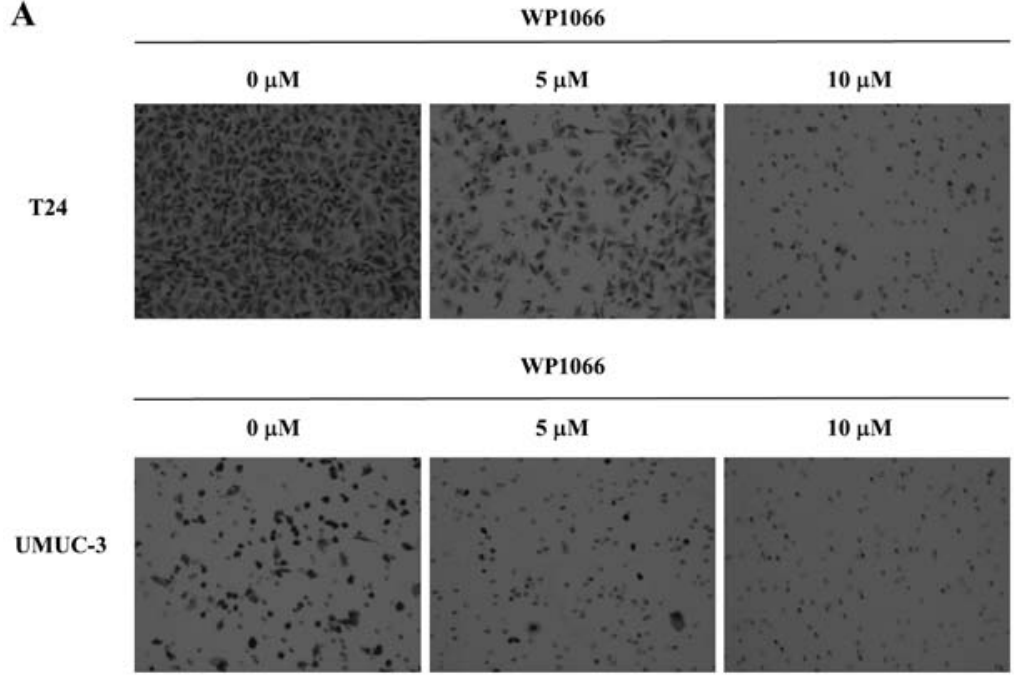

B
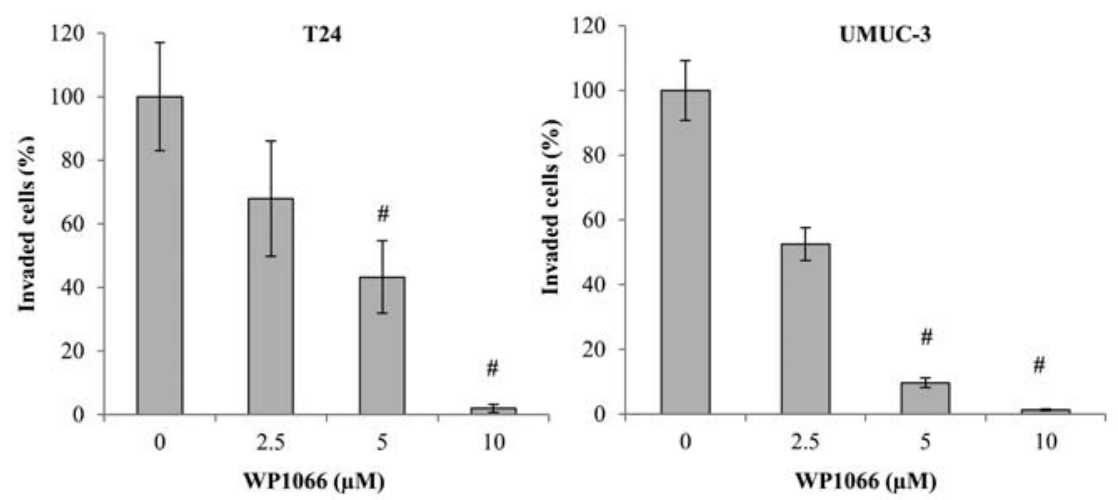

Figure 6. WP1066 suppresses the invasiveness of bladder cancer cells. (A) Representative images of Matrigel invasion and (B) summary of invasion data obtained when T24 and UMUC-3 cells in the upper wells were incubated in serum-free medium and the lower wells were filled with serum-free medium containing WP1066. After $12 \mathrm{~h}$, the number of cells that had invaded through the Matrigel was counted in at least 10 fields/well; " $\mathrm{P}<0.001$.

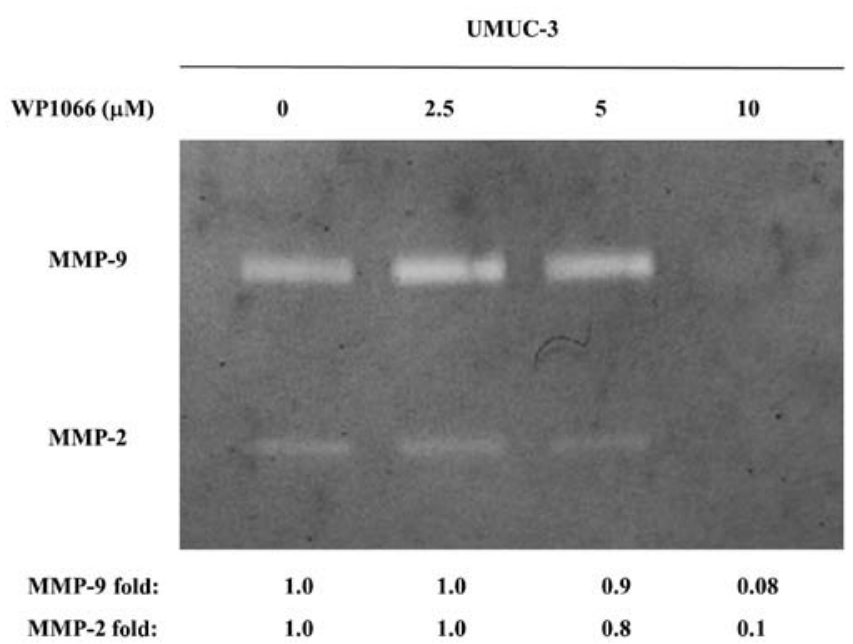

Figure 7. UMUC-3 cells were treated with the indicated concentrations of WP1066 for $12 \mathrm{~h}$, and the conditioned medium was harvested and subjected to a zymography assay. The relative intensities of gelatinolytic activities are shown.

tissues by immunohistochemistry using a phospho-specific STAT3 antibody that recognizes only activated STAT3 and found increased staining in 19 of them (13). In addition,
STAT3 has recently been shown to be an important factor for development of invasive bladder cancer (14). STAT3 transgenic mice exposed to nitrosamine developed invasive cancer from carcinoma in situ (CIS) directly, circumventing the non-invasive papillary stage (14). These studies indicated that STAT3 was deeply implicated in the aggressiveness and progression of bladder cancer. Thus inhibitors of the STAT3 signaling pathway should have enormous potential in the treatment of bladder cancer. In the study reported herein, we investigated the pharmacological antitumor efficacy of the STAT3 inhibitor WP1066 against bladder cancer cells in terms of their proliferation and invasiveness.

WP1066 is one of the commercially available STAT3 inhibitors and has been shown to display a potent inhibitory activity against the upstream protein tyrosine kinase JAK2 (19). Iwamaru et al synthesized WP1066 by modifying the structure of AG490, a compound selected by screening a group of tyrphostins screened for their ability to block STAT3 activity (19). We previously demonstrated that WP1066 inhibited STAT3 activity in renal cancer cells grown both in vitro and in vivo, with a low concentration $(2.5 \mu \mathrm{M})$ of WP1066, significantly inhibiting STAT3 activity and cell viability (18). The present study revealed that the same concentration of WP1066 also significantly inhibited STAT3 
activity and cell viability significantly in both T24 and UMUC3 bladder cancer cells. In contrast, WP1066 application resulted in a reciprocal increase in the activities of ERKs 1 and 2, the kinases responsible for activating the ras/MAP kinase signaling pathway. A similar observation with respect to ERK activity has been made in cell lines derived from renal cell carcinoma, gastric cancer and glioma $(18,28,29)$. ERK activation induced by WP1066 may compromise the antitumor activity of STAT3 inhibition in bladder cancer, as it is a key mitotic signal and promotes proliferation and invasiveness (30).

STAT3 promotes the proliferation of cancer cells by upregulating the expression of the antiapoptotic proteins Bcl-2 and Bcl-xL, and inhibiting it inhibits cancer cell proliferation by downregulating their expression $(11,21)$. Chen et al reported that interrupting the STAT3 signaling pathway in UMUC3 bladder cancer cells using an adenovirus-mediated dominant-negative STAT3 resulted in cell growth inhibition and apoptosis with downregulation of Bcl-2 and Bcl-xL (13). Our results revealing growth inhibition and induction of apoptosis by pharmacological attenuation of STAT3 activity with downregulation of Bcl-2 and Bcl-xL expression in T24 cells was consistent with previous studies $(22,23)$. Another important role of STAT3 in cancer biology is regulating migration and invasive activities $(16,31)$. Ito et al reported that STAT3 regulates the migration and invasion of T24 bladder cancer cells by modulating the expression of matrix metalloproteinase-1 (31). In consistency with their study, the migration and invasiveness of T24 and UMUC-3 bladder cancer cells were decreased with treatment of WP1066. Although WP1066 decreased the proliferation and invasiveness of bladder cancer cells, we could not demonstrate the antitumor efficacy of WP1066 in vivo. In a preliminary study we tried using a xenograft model of bladder cancer cells to examine the antitumor activity of WP1066 in the same way as in our previous study with renal cancer cells (18) but found no significant tumor reduction (data not shown). This is one of the limitations of the present study.

Although cisplatin-based chemotherapy is the first-line treatment for metastatic bladder cancer, chemoresistance remains a major clinical challenge. Activated STAT has been suggested to confer resistance to cisplatin-based chemotherapy by preventing apoptosis, and pharmacological inhibition of STAT3 activity using WP1066 or adenovirus-mediated STAT3 depletion has been shown to potentiate the efficacy of cisplatin $(32,33)$. In addition, recent studies demonstrated the efficacy of molecular targeted therapy using receptor tyrosine kinase inhibitors of the epidermal growth factor receptor (EGFR) family against bladder cancer (34). STAT3 activity has been suggested to be responsible for the resistance to EGFR inhibitors, and targeting STAT3 with a STAT3 decoy decreased cellular viability in models of EGFR inhibitor resistance (35). These results revealed that WP1066 could be a potent agent combined with conventional or targeted therapy and that efficacy of such combinations should be investigated in the near future.

In conclusion, we revealed that the STAT inhibitor WP1066 induces apoptosis of bladder cancer cells and inhibited their viability and invasive activity. These results indicate that using WP1066 to inhibit the STAT3 signaling pathway could be an effective therapeutic strategy against bladder cancer.

\section{References}

1. Ploussard G, Shariat SF, Dragomir A, Kluth LA, Xylinas E, Masson-Lecomte A, Rieken M, Rink M, Matsumoto K, Kikuchi E, et al: Conditional survival after radical cystectomy for bladder cancer: Evidence for a patient changing risk profile over time. Eur Urol 66: 361-370, 2014.

2. Rosenberg JE, Carroll PR and Small EJ: Update on chemotherapy for advanced bladder cancer. J Urol 174: 14-20, 2005.

3. von der Maase H, Sengelov L, Roberts JT, Ricci S, Dogliotti L, Oliver T, Moore MJ, Zimmermann A and Arning M: Long-term survival results of a randomized trial comparing gemcitabine plus cisplatin, with methotrexate, vinblastine, doxorubicin, plus cisplatin in patients with bladder cancer. J Clin Oncol 23: 4602-4608, 2005.

4. van Kessel KE, Zuiverloon TC, Alberts AR, Boormans JL and Zwarthoff EC: Targeted therapies in bladder cancer: An overview of in vivo research. Nat Rev Urol 12: 681-694, 2015.

5. Schindler C and Darnell JE Jr: Transcriptional responses to polypeptide ligands: The JAK-STAT pathway. Annu Rev Biochem 64: 621-651, 1995.

6. Akira S, Nishio Y, Inoue M, Wang XJ, Wei S, Matsusaka T, Yoshida K, Sudo T, Naruto M and Kishimoto T: Molecular cloning of APRF, a novel IFN-stimulated gene factor 3 p91-related transcription factor involved in the gp130-mediated signaling pathway. Cell 77: 63-71, 1994.

7. Yu H, Lee H, Herrmann A, Buettner R and Jove R: Revisiting STAT3 signalling in cancer: New and unexpected biological functions. Nat Rev Cancer 14: 736-746, 2014.

8. Bruserud $\varnothing$, Nepstad I, Hauge M, Hatfield KJ and Reikvam H: STAT3 as a possible therapeutic target in human malignancies: Lessons from acute myeloid leukemia. Expert Rev Hematol 8: 29-41, 2015.

9. Horiguchi A, Oya M, Shimada T, Uchida A, Marumo K and Murai M: Activation of signal transducer and activator of transcription 3 in renal cell carcinoma: A study of incidence and its association with pathological features and clinical outcome. J Urol 168: 762-765, 2002.

10. Kim HS, Park YH, Lee J, Ahn JS, Kim J, Shim YM, Kim JH, Park K, Han J and Ahn MJ: Clinical impact of phosphorylated signal transducer and activator of transcription 3, epidermal growth factor receptor, $\mathrm{p} 53$, and vascular endothelial growth factor receptor 1 expression in resected adenocarcinoma of lung using tissue microarray. Cancer 116: 676-685, 2010.

11. Masuda M, Suzui M, Yasumatu R, Nakashima T, Kuratomi Y, Azuma K, Tomita K, Komiyama S and Weinstein IB: Constitutive activation of signal transducers and activators of transcription 3 correlates with cyclin D1 overexpression and may provide a novel prognostic marker in head and neck squamous cell carcinoma. Cancer Res 62: 3351-3355, 2002.

12. Takemoto S, Ushijima K, Kawano K, Yamaguchi T, Terada A, Fujiyoshi N, Nishio S, Tsuda N, Ijichi M, Kakuma T, et al: Expression of activated signal transducer and activator of transcription-3 predicts poor prognosis in cervical squamous-cell carcinoma. Br J Cancer 101: 967-972, 2009.

13. Chen CL, Cen L, Kohout J, Hutzen B, Chan C, Hsieh FC, Loy A, Huang V, Cheng G and Lin J: Signal transducer and activator of transcription 3 activation is associated with bladder cancer cell growth and survival. Mol Cancer 7: 78, 2008.

14. Ho PL, Lay EJ, Jian W, Parra D and Chan KS: Stat3 activation in urothelial stem cells leads to direct progression to invasive bladder cancer. Cancer Res 72: 3135-3142, 2012.

15. Sun Y, Cheng MK, Griffiths TR, Mellon JK, Kai B, Kriajevska M and Manson MM: Inhibition of STAT signalling in bladder cancer by diindolylmethane: Relevance to cell adhesion, migration and proliferation. Curr Cancer Drug Targets 13: 57-68, 2013.

16. Zhang N, Duan WD, Leng JJ, Zhou L, Wang X, Xu YZ, Wang XD, Zhang AQ and Dong JH: STAT3 regulates the migration and invasion of a stem-like subpopulation through microRNA-21 and multiple targets in hepatocellular carcinoma. Oncol Rep 33: 1493-1498, 2015 .

17. Schneider CA, Rasband WS and Eliceiri KW: NIH Image to ImageJ: 25 years of image analysis. Nat Methods 9: 671-675, 2012.

18. Horiguchi A, Asano T, Kuroda K, Sato A, Asakuma J, Ito K, Hayakawa M, Sumitomo M and Asano T: STAT3 inhibitor WP1066 as a novel therapeutic agent for renal cell carcinoma. Br J Cancer 102: 1592-1599, 2010. 
19. Iwamaru A, Szymanski S, Iwado E, Aoki H, Yokoyama T, Fokt I, Hess K, Conrad C, Madden T, Sawaya R, et al: A novel inhibitor of the STAT3 pathway induces apoptosis in malignant glioma cells both in vitro and in vivo. Oncogene 26: 2435-2444, 2007.

20. Horiguchi A, Asano T, Asano T, Ito K, Sumitomo M and Hayakawa M: Pharmacological inhibitor of fatty acid synthase suppresses growth and invasiveness of renal cancer cells. J Urol 180: 729-736, 2008.

21. Horiguchi A, Oya M, Marumo K and Murai M: STAT3, but not ERKs, mediates the IL-6-induced proliferation of renal cancer cells, ACHN and 769P. Kidney Int 61: 926-938, 2002.

22. Bhattacharya S, Ray RM and Johnson LR: STAT3-mediated transcription of Bcl-2, Mcl-1 and c-IAP2 prevents apoptosis in polyamine-depleted cells. Biochem J 392: 335-344, 2005.

23. Chang Q, Bournazou E, Sansone P, Berishaj M, Gao SP Daly L, Wels J, Theilen T, Granitto S, Zhang X, et al: The IL-6/JAK/Stat3 feed-forward loop drives tumorigenesis and metastasis. Neoplasia 15: 848-862, 2013.

24. Zhou X, Ren Y, Liu A, Han L, Zhang K, Li S, Li P, Li P, Kang C, Wang X, et al: STAT3 inhibitor WP1066 attenuates miRNA-21 to suppress human oral squamous cell carcinoma growth in vitro and in vivo. Oncol Rep 31: 2173-2180, 2014.

25. Zhang X, Sun Y, Pireddu R, Yang H, Urlam MK, Lawrence HR, Guida WC, Lawrence NJ and Sebti SM: A novel inhibitor of STAT3 homodimerization selectively suppresses STAT3 activity and malignant transformation. Cancer Res 73: 1922-1933, 2013.

26. Degoricija M, Situm M, Korać J, Miljković A, Matić K, Paradžik M, Marinović Terzić I, Jerončić A, Tomić $S$ and Terzić J: High NF- $\kappa \mathrm{B}$ and STAT3 activity in human urothelial carcinoma: A pilot study. World J Urol 32: 1469-1475, 2014.

27. Chen RJ, Ho YS, Guo HR and Wang YJ: Rapid activation of Stat 3 and ERK1/2 by nicotine modulates cell proliferation in human bladder cancer cells. Toxicol Sci 104: 283-293, 2008.

28. Sai K, Wang S, Balasubramaniyan V, Conrad C, Lang FF, Aldape K, Szymanski S, Fokt I, Dasgupta A, Madden T, et al Induction of cell-cycle arrest and apoptosis in glioblastoma stem-like cells by WP1193, a novel small molecule inhibitor of the JAK2/STAT3 pathway. J Neurooncol 107: 487-501, 2012.
29. Judd LM, Menheniott TR, Ling H, Jackson CB, Howlett M, Kalantzis A, Priebe W and Giraud AS: Inhibition of the JAK2/STAT3 pathway reduces gastric cancer growth in vitro and in vivo. PLoS One 9: e95993, 2014.

30. Monami G, Gonzalez EM, Hellman M, Gomella LG, Baffa R, Iozzo RV and Morrione A: Proepithelin promotes migration and invasion of 5637 bladder cancer cells through the activation of ERK1/2 and the formation of a paxillin/FAK/ERK complex. Cancer Res 66: 7103-7110, 2006.

31. Itoh M, Murata T, Suzuki T, Shindoh M, Nakajima K, Imai K and Yoshida K: Requirement of STAT3 activation for maximal collagenase-1c (MMP-1) induction by epidermal growth factor and malignant characteristics in T24 bladder cancer cells. Oncogene 25: 1195-1204, 2006.

32. Han Z, Hong Z, Gao Q, Chen C, Hao Z, Ji T, Hu W, Yan Y, Feng J, Liao S, et al: A potent oncolytic adenovirus selectively blocks the STAT3 signaling pathway and potentiates cisplatin antitumor activity in ovarian cancer. Hum Gene Ther 23: 32-45, 2012.

33. Zhou X, Ren Y, Liu A, Jin R, Jiang Q, Huang Y, Kong L, Wang X and Zhang L: WP1066 sensitizes oral squamous cell carcinoma cells to cisplatin by targeting STAT3/miR-21 axis. Sci Rep 4: 7461,2014

34. Mooso BA, Vinall RL, Mudryj M, Yap SA, deVere White RW and Ghosh PM: The role of EGFR family inhibitors in muscle invasive bladder cancer: A review of clinical data and molecular evidence. J Urol 193: 19-29, 2015.

35. Sen M, Joyce S, Panahandeh M, Li C, Thomas SM, Maxwell J, Wang L, Gooding WE, Johnson DE and Grandis JR: Targeting Stat 3 abrogates EGFR inhibitor resistance in cancer. Clin Cancer Res 18: 4986-4996, 2012 